\title{
Adherence-monitoring practices by private healthcare sector doctors managing HIV and AIDS patients in the eThekwini metro of KwaZulu-Natal
}

\author{
${ }^{a}$ Naidoo P, MMedSci (Pharmacology) ${ }^{\mathrm{b}}$ Taylor M, PhD b Jinabhai CC, PhD \\ a School of Pharmacy and Pharmacology, University of KwaZulu-Natal, South Africa

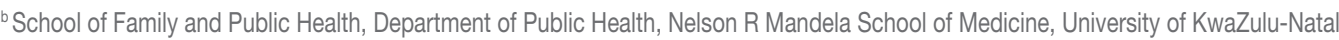 \\ Correspondence to: P Naidoo, e-mail: naidoopj@ukzn.ac.za \\ Keywords: private sector; doctors; adherence; monitoring; HIV/AIDS
}

\begin{abstract}
SA Fam Pract 2010;52(5):471-475

Background: The danger of poor adherence to treatment by patients with HIV infection is that poor adherence correlates with clinical and virological failure. Understanding how private-sector doctors monitor adherence by their HIV-infected patients could assist in developing interventions to improve adherence by these patients. Information about such practices amongst private-sector doctors in the province of KwaZulu-Natal, however, is limited. This study was, therefore, undertaken to assess the private-sector doctor adherence-monitoring practices of HIV-infected patients in the eThekwini metro of KwaZulu-Natal.

Methods: A descriptive cross-sectional study was undertaken amongst private general practitioners (GPs) and specialists managing HIV/AIDS patients in the eThekwini metro. Anonymous semi-structured questionnaires were used to investigate adherence-monitoring practices by these doctors and their strategies to improve adherence.

Results: A total of 171 doctors responded, with over $75 \%$ in practice for over 11 years and $78.9 \%$ indicating that they monitored adherence. A comparison between the GPs and the specialists found that $82.6 \%$ of the GPs monitored adherence compared with $63.6 \%$ of the specialists $(p=0.016)$. The doctors used several approaches, with $60.6 \%$ reporting the use of patient self-reports and $18.3 \%$ reporting the use of pill counts. A total of $68.7 \%$ of the doctors indicated that their adherence monitoring was reliable, whilst $19.7 \%$ indicated that they did not test the reliability of their monitoring tools. The most common strategy used to improve adherence by their patients was through counselling. Other strategies included alarm clocks, SMSs, telephone calls to the patients, the encouragement of family support and the use of medical aid programmes.
\end{abstract}

Conclusions: Private-sector doctors managing HIV/AIDS patients in the eThekwini metro of KwaZulu-Natal do monitor adherence and employ strategies to improve adherence.

(P) Peer reviewed. (Submitted: 2009-10-19, Accepted: 2009-12-21). ๑ SAAFP

\section{Introduction}

The success of antiretroviral (ARV) therapy (ART) is highly dependent on the ability of the patient to adhere to prescribed treatment regimens. ${ }^{1}$ The advent of highlyactive ARV therapy (HAART) ushered in a new era in the management of the HIV/AIDS pandemic with new drugs, new strategies and enthusiasm from clinicians and patients. What soon became evident, however, was the vital importance of patient adherence to prescribed medication to obtain full therapeutic benefits. ${ }^{2}$ Adherence is associated with patient factors, the regimen, the clinical setting and the strength of the provider-patient relationship ${ }^{3}$ and is an equal partnership between the patient and her or his healthcare provider. $^{4}$
Various factors are associated with poor adherence, including the following: low levels of literacy; certain agerelated challenges (such as vision loss and cognitive impairment); psychosocial issues (such as depression, homelessness, lower social support, stressful life events, dementia and psychosis); active (but not a history of) substance abuse, particularly for patients experiencing recent relapse; stigma; difficulty with the taking of the medication (such as trouble swallowing the pills and daily schedule issues); complex regimens (such as pill burden, dosing frequency and food requirements); adverse drug effects; and treatment fatigue. ${ }^{5-8}$ For chronic conditions, long-term and sometimes complex regimens make it critical for adherence to be sustained over time. In HIV-infected persons, non-adherence to ART is shown to be one of 
the most important predictors of therapeutic failure. ${ }^{9}$ The danger of poor adherence by patients with HIV infection is that poor adherence correlates with clinical and virological failure. ${ }^{10}$

Information provided by health professionals and patient understanding about HIV infection and their specific ARV regimens are critical. Patients who understand the rationale for ART and the role of adherence in the development of resistance and treatment failure report higher adherence levels than those without this information. ${ }^{11}$ Patient nonadherence can take many forms, since the advice given to patients by their healthcare professionals to cure or control the disease is too often misunderstood or carried out incorrectly, forgotten or even completely ignored.12 Reinforcement by health professionals of information provided verbally, together with written information to take home, and checking that the information provided is understood are important in cases where the information is normally misunderstood by the patients.

One study found that $13 \%$ of the patients were not taking their medication properly despite believing that they were. ${ }^{11}$ A South African study done in a managed healthcare setting, however, found that $31.1 \%$ of the doctors failed to note non-adherence as a cause of treatment failure. ${ }^{13}$

Various factors affect adherence to ART and it is, therefore, important for healthcare providers to explore these factors and to foster a trusting relationship before offering therapy, so that the success of treatment can be maximised. Numerous medication alert strategies, such as programmable watches and SMS text messaging, play an important role in patients who cite forgetfulness as a reason for missing their medication. ${ }^{11}$ Other strategies, such as telephone reminders, pill diaries and counts, medication containers and the enlistment of family and friends as reminders, have also been shown to improve adherence in other disease areas. ${ }^{11}$

A study done in KwaZulu-Natal amongst private-sector doctors concluded that client motivation and close relationships with their providers were crucial to the success of the programmes, ${ }^{14}$ whilst another study found that experienced physicians achieved better patient adherence..$^{15}$ The average rate of adherence varied according to the methods used to assess adherence and the groups studied, but appeared to be approximately $70 \% \cdot{ }^{16-18}$

An understanding of how private-sector doctors monitor adherence to treatment by their HIV-infected patients and of the strategies that they use to improve adherence could assist in developing interventions to improve adherence by these patients. Information about such practices in the province of KwaZulu-Natal is, however, limited or even lacking. This study was, therefore, undertaken to assess the private-sector doctor adherence-monitoring practices of HIV-infected patients in the eThekwini metro of KwaZulu-Natal.

\section{Methods}

\section{Study design, study site and sample population}

A descriptive cross-sectional study was undertaken in the eThekwini metro of KwaZulu-Natal. A comprehensive list of 1255 general practitioners (GPs) and specialists practising in the eThekwini metro was obtained from the Medpages Directory, the KwaZulu-Natal Managed Care Coalition (a private-doctor group), doctors' guilds, the Lancet Clinic Courier database and the Southern African HIV Clinicians Society. Some of the specialist doctors were excluded after they indicated that their contact with HIV/AIDS patients was minimal and felt that it would, therefore, be inappropriate for them to participate. These included gynaecologists, surgeons, occupational health doctors, psychiatrists, cardiologists, anaesthetists, ophthalmologists, plastic surgeons, critical care doctors and doctors working in the trauma units of private hospitals.

The study was divided into two phases. Phase 1 included 235 doctors who indicated that they managed HIV and AIDS patients, 190 of whom indicated their willingness to participate in Phase $2 .{ }^{19}$ These doctors were surveyed by using semi-structured questionnaires after obtaining their consent. The questionnaires were coded so that no identification would be possible and to ensure anonymity and confidentiality. The study was undertaken in the province of KwaZulu-Natal, since this is the province with the largest provincial population in South Africa, with just over 10 million people $(20.9 \%$ of the total population of 47.9 million), ${ }^{20}$ and it is the province with the highest prevalence of HIV, as indicated by antenatal clinic attendee data $(39.1 \%$ in 2006, with the national figure being $29.1 \%$ ). ${ }^{21}$

The study included data on the demographic profiles of the doctors, their adherence-monitoring practices, the type of adherence-monitoring tools that they used and the strategies that they employed to improve adherence by their HIV/AIDS patients. These took the form of closed-ended questions. Most of the questionnaires were hand-delivered and collected on completion. A few of the questionnaires were faxed and, when completed, were faxed back.

The data were captured and analysed with the SPSS version 15.0. Pearson chi square was used to determine the $p$ value. A $p$ value of less than 0.05 was considered statistically significant. 


\section{Ethics clearance}

Approval to conduct the study was obtained from the Nelson R Mandela School of Medicine, Faculty of Medicine, College of Health Science, University of KwaZulu-Natal. The ethics number is $\mathrm{H} 138 / 03$.

\section{Results}

\section{Demographic data}

A total of 171 doctors responded, $138(80.7 \%)$ of whom were GPs and the majority of whom were males. A total of $67 \%$ (108) of the respondents was in the age range of 30 to 50 years and over $75 \%$ of the doctors had been in practice for over 11 years.

\section{Adherence-monitoring practices}

Of the private-sector doctors who responded, $78.9 \%$ indicated that they monitored adherence.

A comparison between the GPs and the specialists showed that $82.6 \%$ of the GPs monitored adherence, whilst about two-thirds (63.6\%) of the specialists monitored adherence $(p=0.016)$.

The doctors used several approaches to monitor adherence (Figure 1), with the majority of them $(60.6 \%)$ reporting the use of patient self-reports compared with only $18.3 \%$ reporting the use of pill counts as a means of monitoring adherence.

Figure 1: Tools used by private-sector doctors to monitor adherence in the eThekwini metro of KZN

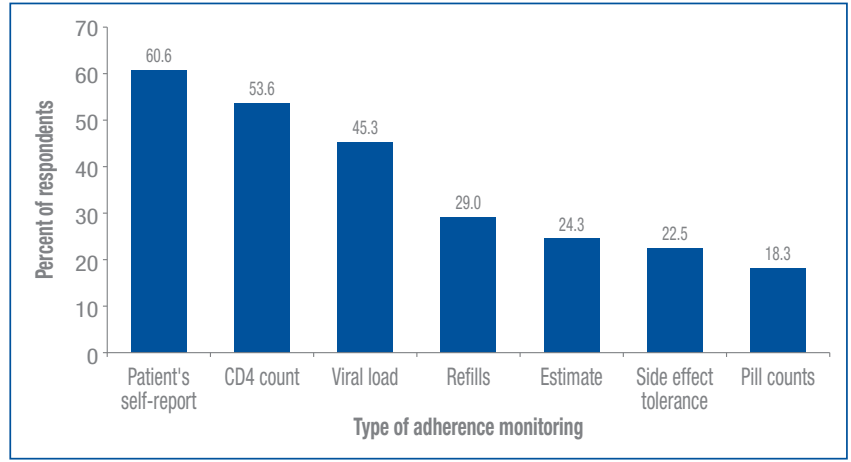

Table I: Comparison of GP and specialist adherence-monitoring tools

\begin{tabular}{|l|c|c|c|c|c|}
\hline Monitoring tool & N & \multicolumn{1}{|c|}{ GPs } & Specialists & Total & P value \\
\hline Pill count & 169 & $29(21.3 \%)$ & $2(6.1 \%)$ & $31(18.3 \%)$ & 0.042 \\
\hline CD4 & 170 & $75(54.7 \%)$ & $16(48.5 \%)$ & $91(53.5 \%)$ & 0.517 \\
\hline Viral load & 170 & $63(46.0 \%)$ & $14(42.4 \%)$ & $77(45.3 \%)$ & 0.712 \\
\hline Refill & 169 & $43(31.6 \%)$ & $6(18.2 \%)$ & $49(29.0 \%)$ & 0.127 \\
\hline Estimate & 169 & $35(25.7 \%)$ & $6(18.2 \%)$ & $41(24.3 \%)$ & 0.364 \\
\hline Side effects & 169 & $34(25.0 \%)$ & $4(12.1 \%)$ & $38(22.5 \%)$ & 0.112 \\
\hline Self-report & 170 & $86(62.8 \%)$ & $17(51.5 \%)$ & $103(60.6 \%)$ & 0.235 \\
\hline
\end{tabular}

A comparison between the GP and the specialist use of monitoring tools (Table I) showed a significant result for adherence monitoring by pill count. A similar percentage of the GPs and specialists, however, used laboratory markers, such as CD4 counts and viral load, to monitor adherence.

Of the respondents who monitored adherence, $68.7 \%$ indicated that their adherence monitoring was reliable, $11.6 \%$ indicated that their adherence monitoring was not reliable and $19.7 \%$ indicated that they did not test the reliability of their adherence monitoring tools.

\section{Strategies to improve adherence}

The most common strategy used by doctors to improve adherence by their patients was educating patients, which they did by talking to them. This was indicated by $71.2 \%$ of the doctors, who indicated that they always or often counselled their patients on adherence, the state of their disease, side effects, nutrition, various types of interactions to alcohol abuse and complementary medicines. A total of 96.4\% of the GPs and $93.9 \%$ of the specialists indicated that it was not time-consuming to counsel their patients.

Other strategies used by fewer of the doctors to improve adherence by their patients included the use of alarm clocks (14.2\%) and SMSs (9.5\%), whilst others (7.1\%) phoned their patients, encouraged family support and used medical-aid programmes.

\section{Discussion}

The respondents in this study used many strategies to monitor adherence, such as self-reports, CD4 counts, viral loads, doctor estimates, refills, side effects and pill counts, with just over two-thirds considering their monitoring tools to be reliable. Doctors managing HIV-infected patients should have an accurate and relatively simple method of monitoring adherence to ensure good clinical outcome. It is well known that provider estimates of adherence are inaccurate and often lead to the incorrect assumption of good adherence. ${ }^{16}$ Several strategies to monitor adherence exist, including pill counts, electronic monitors and selfreport questionnaires. The methods used to monitor adherence, however, have both strengths and weaknesses and can yield widely varying results. ${ }^{22,23}$ Patient selfreports seemed to be used by the majority of the doctors in this study. Even though this is a relatively simple and efficient method of assessing adherence in clinical practice compared with objective measures, such as micro electromechanical systems (MEMS) caps and unannounced pill counts, self-assessment is a less sensitive measure of nonadherence, since patients tend to overestimate adherence when self-reporting, while electronic monitoring can be an inaccurate measure of non-adherence, since patients can 
remove multiple doses at a single time or not take a dose when it is removed. ${ }^{22,24}$ Many of the adherence-monitoring methods are also limited in that they fail to detect nonadherence related to not following dietary restrictions or dosing intervals. ${ }^{22}$ There is thus no gold standard by which to monitor adherence.

To assess adherence accurately, clinicians should develop a collaborative and non-judgmental relationship with their patients. The best strategy when asking patients about their adherence is not in the specifics of the tool used but in taking the time to enquire regularly about adherence in an open manner. Many patients otherwise simply respond by what they believe their clinicians want to hear, namely that they have been perfectly adherent. ${ }^{16} \mathrm{~A}$ trilogy of information, motivation and behavioural skills is essential in ensuring adherence to HAART. ${ }^{25}$

Laboratory markers, such as CD4 counts and viral loads, were also used by the respondents to monitor adherence. The main goal of ART is to prevent HIV-related morbidity and mortality and many studies have shown a strong correlation between adherence and clinical outcomes and/ or laboratory markers (notably CD4 counts). ${ }^{16}$ Adherence is associated with CD4 counts, as demonstrated by one study in which respondents who had adherence equal to or greater than $95 \%$ had a mean increase in their CD4 count of 83 cells/ $\mu$ l compared with those with a less than $95 \%$ adherence level, who had a mean increase of 6 cells $/ \mu .^{10}$ Whilst another study done amongst Brazilian HIV-infected patients concluded that, although self-reported adherence was not a sufficiently precise predictor of treatment success to substitute for viral-load monitoring, it did help to identify non-adherence, thereby providing an opportunity for early intervention. ${ }^{1}$ In addition, in a study done in Uganda with self-paying patients who were followed for 90 days after the initiation of ART, mean adherence measured through 3-day self-reports, 30-day self-reports, unannounced pill counts and MEMS caps was found to be $92.9 \%, 91.6 \%, 91.9 \%$ and $90.35 \%$, respectively. ${ }^{26}$

Patient education about the multifaceted aspects of ART is a crucial component of care..$^{27}$ In this study, the doctors used many strategies to improve adherence, with over $70 \%$ of the doctors emphasising the importance of educating their patients to improve adherence. The doctors counselled their HIV-infected patients on a wide range of topics relevant to adherence, thereby enforcing the information and education to improve their knowledge about their drug therapy and disease state. The topics varied from counselling on adherence, disease state, side effects, nutrition, various types of interactions to alcohol abuse and complementary medicines. The vast majority of the doctors indicated that time was not an issue when it came to counselling their HIVinfected patients.
Extensive counselling, especially for patients who are nonadherent, can be very time-consuming but, with over $93 \%$ of the doctors stating that it was not time-consuming to counsel, questions on the quality of counselling sessions should be raised. Interventions to improve ARV adherence involve dedicated time with patients to plan for and support medication adherence with effective interventions characterised by an initial educational session, including individualised collaborative medication planning with follow-up sessions maintained regularly over the course of treatment. ${ }^{16}$ With the limited time sometimes available for doctor-patient consultation and with the availability of other skilled allied professionals, doctors could work towards a multidisciplinary approach to HIV care. Nurse-led and pharmacist-led programmes, for example, show improved virological response and adherence levels, respectively, in people receiving HAART. ${ }^{11}$

Other strategies, such as alarm clocks and SMSs, were used by fewer of the doctors. It would be prudent for doctors, however, to encourage the use of devices that help patients to adhere to their treatment regimens, such as pill boxes and reminder devices. Most of them are simple, inexpensive and easy to integrate into the routine care of patients on ART. Patients taking pill boxes to appointments can help clinicians to monitor for recent non-adherence. Reminder devices, such as alarms on watches and cell phones, SMSs, beepers or any other electronic reminder devices, are especially important for patients who forget to take their medicine. A small minority of doctors in this study stated that they phoned their patients and encouraged family support to improve adherence by their patients. These practices should be encouraged as a means of improving adherence to the treatment of HIV-infected patients. ${ }^{11}$

\section{Conclusions and recommendations}

The private-sector doctors in this study who manage HIV and AIDS patients do monitor for adherence using different monitoring tools, although the reliability of the tools has not been assessed by all the doctors. They do have strategies to improve adherence by their patients, but they should do more in this area.

Doctors have an important role in motivating and supporting their patients to adhere to ARV treatment. They should ensure that their patients are well educated and counselled about their disease state and management. Adherence to management can be effectively monitored by doctors if good therapeutic relationships are developed with the patients. A combination of methods appropriate to the patients and clinical settings should also be used to improve adherence. Adherence interventions should include dedicated educational sessions with every patient 
and a programme of providing the necessary support in an open and non-judgmental manner throughout the course of treatment. In this way, problems can be addressed and adherence devices supplied or recommended where appropriate.

\section{Limitations}

The findings of this study should be interpreted in the light of its limitations. This was a cross-sectional study and there is thus not strong evidence of causal relationship. The size of the sample and the sampling method used do not allow for the findings to be generalised to all private-sector doctors practising in the eThekwini metro of KwaZulu-Natal. Finally, the validity of data could be reduced because of this being a self-reported questionnaire survey.

\section{References:}

1. Garcia R, Badaro R, Netto EM, et al. Cross sectional study to evaluate factors associated with adherence to antiretroviral therapy by Brazilian HIV-infected patients. AIDS Res Hum Retroviruses. 2006 Dec 22(12):1248-52.

2. Naidoo P. Factors influencing HAART adherence among private health care sector patients in a suburb of the Ethekwini Metro. Afr J Prm Health Care Fam Med. 2009;1(1); Art.\#12,4 pp. DOI: 10.4102/phcfm.v111.12.

3. Schneider J, Kaplan SH, Greenfield S, et al. Better physician-patient relationships are associated with higher reported adherence to antiretroviral therapy in patients with HIV infection. J Gen Intern Med. 2004;19(11):1096-103.

4. McAllister J. Antiretroviral drug therapy for HIV-infection: Developing an adherence framework. [cited 2009 Aug 31]. Available from http://www. clininfo.health.nsw.gov.au/hospolic/stvincents/2000/drug_therapy.html.

5. Marcus EN. The silent epidemic: The health effects of illiteracy. N Engl J Med. 2006;355(4):339-41.

6. Van Eijken M, Tsang S, Wensing M, et al. Interventions to improve medication compliance in older patients living in the community: A systematic review of the literature. Drugs Aging. 2003;20(3):229-40.

7. Halkitis PN, Shrem MT, Zade DD, et al. The physical, emotional and interpersonal impact of HAART: Exploring the realities of HIV seropositive individuals on combination therapy. J Health Psychol. 2005;10(3):345-58.

8. Carr RL, Gramling LF. Stigma: A health barrier for women with HIV/AIDS. J Assoc Nurses AIDS Care. 2004;15(5):30-9.

9. Murri R, Ammassari A, Trotta MP, et al. Patient-reported and physicianestimated adherence to HAART. J Gen InternI Med. 2004 Nov 19(11):1104-10.

10. Paterson DL, Swindells S, Mohr J, et al. Adherence to protease inhibitor therapy and outcomes in patients with HIV infection. Ann Intern Med. 2000;133:21-30.

11. British HIV Association. How can high adherence be promoted? [cited 2009 Dec 11]. Available from http://209.85.229.132/search?q=cache:_czu1ykUfwJ:www.bhiva.org/cms1192487.aspx+bhiva+british+HIV+association+a dherence+be+promoted\&cd=1\&hl=en\&ct=clnk\&gl=za.
12. Martin LR, Williams SL, Haskard KB, DiMatteo MR. The challenge of patient adherence. Ther Clin Risk Manag. 2005 Sep 1(3):189-99.

13. Sifris D, Van Bassen A, Myhre J. Clinical practices impacting the durability of HAART in resource-limited settings: A five year South African managed healthcare study. 16th International Conference on AIDS; 2006 Aug 13-18; Toronto, Canada); 16; abstract no.WEPE0132.

14. Ahmed FA, Mthiyane TC, Rustomjee R. Lessons learnt from ARV management in the private sector. Int Conf AIDS. 2004 Jul 11-16; 15:Abstract no. ThPeB7160.

15. Toke S, Barfod TS, Frederick M, Hecht FM, Cecilie Rubow C, Gerstoft J. Physicians' communication with patients about adherence to HIV medication in San Francisco and Copenhagen: A qualitative study using grounded theory. BMC Health Services Research. 2006, 6:154doi:10.1186/14726963-6-154. [cited 2009 Dec 11]. Available from http://www.biomedcentral. com/1472-6963/6/154.

16. Edward L, Machtinger EL, Bangsberg DR. Adherence to HIV antiretroviral therapy. HIV InSite Knowledge Base Chapter May 2005. [updated $2007 \mathrm{Jul}$; cited 2009 Sep 6]. Available from http://www.aids-ed.org/ aidsetc?page $=\mathrm{cm}-302$ _adhere.

17. Golin CE, Liu H, Hays RD, et al. A prospective study of predictors of adherence to combination antiretroviral medication. J Gen Intern Med. 2002 Oct 17(10):756-65.

18. Edward L, Machtinger EL, Bangsberg DR. Adherence to HIV antiretroviral therapy. HIV InSite Knowledge Base Chapter May 2005. [updated 2006 Jan; cited 2009 Dec 11]. Available from http://hivinsite.ucsf.edu/ InSite? page=kb-03-02-09.

19. Naidoo P, Jinabhai CC, Taylor M. Identification of sources for seeking HIV and AIDS information amongst private sector doctors. (in press SA Fam Pract 2009).

20. SouthAfrica.info Gateway to the nation. [cited 2008 Dec 23]. Available from http://www.southafrica.info/about/people/popprov.htm.

21. South Africa HIV and AIDS stats. [cited 2009 Jun 4]. Available from http:// www.avert.org/safricastats.htm.

22. Bartlett JA. Addressing the challenges of adherence. J Acquir Immune Defic Syndr. 2002;29(suppl 1):S2-S10.

23. Bangsberg DR, Hecht FM, Charlebois ED, et al. Adherence to protease inhibitors, HIV-1 viral load, and development of drug resistance in an indigent population. AIDS. 2000;14:357-66.

24. Chesney MA, Ickovics JR, Chambers DB, et al. Self-reported adherence to antiretroviral medications among participants in HIV clinical trials: The AACTG adherence instruments. AIDS Care. 2000;12:255-66.

25. Garcia R, Garcia ML, Gorender M, Badaro R. The importance of the doctorpatient relationship in adherence to HIV/AIDS treatment: A case report. Braz J Infect Dis. 2005;9(3):251-6.

26. Oyugi J, Byakika-usziime J, Kitko C, et al. Self-reported adherence measures are feasible and valid compared to multiple objective measures in Kampala, Uganda2003.

27. Douaihy AB, Stowell KR, Bui T, Daley D, Salloum I. HIV/AIDS and homelessness, Part 2: Treatment issues. AIDS Read. 2005 Nov 15(11):604-6,611-613,618. 